\title{
A State of the Art Review of Modal-Based Damage Detection in Bridges: Development, Challenges, and Solutions
}

\author{
John J. Moughty * and Joan R. Casas * \\ Department of Civil and Environmental Engineering, Technical University of Catalonia-BarcelonaTech, \\ 08034 Barcelona, Spain \\ * Correspondence: john.james.moughty@upc.edu (J.J.M.); joan.ramon.casas@upc.edu (J.R.C.); \\ Tel.: +34-658-172-114 (J.J.M.); +34-93-401-6513 (J.R.C.)
}

Academic Editor: Gangbing Song

Received: 1 April 2017; Accepted: 9 May 2017; Published: 13 May 2017

\begin{abstract}
Traditionally, damage identification techniques in bridges have focused on monitoring changes to modal-based Damage Sensitive Features (DSFs) due to their direct relationship with structural stiffness and their spatial information content. However, their progression to real-world applications has not been without its challenges and shortcomings, mainly stemming from: (1) environmental and operational variations; (2) inefficient utilization of machine learning algorithms for damage detection; and (3) a general over-reliance on modal-based DSFs alone. The present paper provides an in-depth review of the development of modal-based DSFs and a synopsis of the challenges they face. The paper then sets out to addresses the highlighted challenges in terms of published advancements and alternatives from recent literature.
\end{abstract}

Keywords: structural health monitoring; damage detection; modal analysis; machine learning; non-stationary analysis; signal processing

\section{Introduction}

An aging road and rail infrastructure has initiated and sustained a considerable body of research material over recent decades in the pursuit of enhanced certainty of structural condition and safety. Many bridge structures are now subjected to traffic loading conditions far in advance of their original design criteria. This continual increase in operational condition loading accelerates structural fatigue and reduces service-life; so much so that structural fatigue is no longer a single-structure problem, but a national network issue [1].

Despite the magnitude of academic work on bridge damage detection and identification, the vast majority of in-service bridge data is still collected via visual inspections. These methods are considered to be tried and trusted within the bridge-owner community, but possess several limitations in their scope and attain inconsistent results due to the disparity of inspector competency. International inconsistencies are also prevalent with regards to damage parameter measurement, non-destructive testing methods, condition state definitions, and inspection frequencies [2], which has resulted in traditional inspection methods being perceived as overly subjective, resulting in recent measures being taken by the international research community to standardise cross-border practices and definitions $[3,4]$.

Recent figures estimate Europe's highway bridge count to be circa one million [5], which would infer that periodic visual inspections alone are not a practical option, and this has led to many bridge-owners calling for increased integration of monitoring techniques with standard inspections [6]. Moreover, as maintenance costs dramatically increase when damage is left unattended, it is imperative that bridge-owners detect such changes as soon as possible and conduct the necessary maintenance 
work in a timely manner to minimise life cycle costs. To this end, extensive research in the areas of bridge maintenance and maintenance scheduling [7-9], in addition to reliability analysis [10-13], has been conducted to assist the challenge, although this is also a work in progress. For example, a traditionally popular method of maintenance scheduling is to use deterministic functions to conduct time-dependant reliability analyses to model structural deterioration [14]; however, this method of scheduling has been shown to neglect the time-dependency of uncertainty in resistance, which increases over time [15]. Yang et al. [16] demonstrated that scheduling maintenance actions in this way causes substantial maintenance delays, resulting in increased deterioration and repair costs for more bridges than previously thought.

A more efficient option for maintenance scheduling is to use known performance indicators that represent the current structural condition and administer maintenance works once the performance indicators breach defined thresholds, in a method known as Reliability-Based Scheduling [17]. Traditionally, the performance indicators used for monitoring purposes have been modal-based parameters. Many techniques incorporating modal parameters have been proposed, developed, and expanded upon over the years, several of which are detailed in the following review papers [18-28]. However, the accurate determination of modal parameters from in-service bridges has proven to be quite a non-trivial task that faces numerous challenges and limitations. The present review paper differentiates from its predecessors by firstly identifying the most prevalent challenges and limitations faced by modal-based Damage Sensitive Features (DSFs) and by subsequently presenting novel solutions specific to each contentious area. The ultimate aim of such methodologies is to fulfil four stages of assessment, as proposed by Rytter [29] (see Table 1). It is believed that by using vibration data alone (which is the focus of this study), it is possible to achieve Levels 1 to 3; however, some authors have stated that vibration-based methodologies alone are inadequate for predicting the remaining service life of a structure (Level 4) without the incorporation of a sophisticated numerical model [30].

The structure of the paper is thus divided into two main sections, with the first section presenting the development of modal-based damage detection methodologies through the years and discussing their challenges and limitations. The second section is further sub-divided in order to deal with each identified issue individually and to discuss potential remedies that have been recently proposed in the literature.

Table 1. Damage identification levels.

\begin{tabular}{ccc}
\hline Level & Label & Description \\
\hline 1 & Detection & Detection of damage in structure \\
2 & Localization & Localization of detected damage \\
3 & Assessment & Quantification of damage severity \\
4 & Prediction & Estimation of remaining service life \\
\hline
\end{tabular}

\section{Modal Based Damage Detection: Development \& Challenges}

\subsection{Development of Modal-Based Damage Sensitive Features}

As this paper's aim is to highlight the most prevalent challenges regarding modal-based DSFs and their possible solutions proposed in recent literature, the present section shall initiate this objective by introducing numerous DSFs and detailing their theoretical background, development and application.

\subsubsection{Natural Frequencies}

The original attempt to discern damage in structures was proposed by Adams et al. [31] in the late 1970s, and was later expanded by Crawly \& Adams [32], where frequency shifts were used to detect damage. Salawu [33] also stated that the natural frequency approach is potentially useful for the routine integrity assessment of structures, given its ease of application and the global nature of the identified frequencies. Generally, an assumption of linear-stationary structural response is made to 
allow the use of a Fourier-type transform to obtain the frequency content of measured vibration data, prior to employing peak-peaking to discern modal frequencies. The global nature of modal frequencies may not always lend itself well to damage localisation in complex structures [34-36], although they can be utilised to do so for more regular geometries when given the undamaged and damaged states, in addition to a sufficient number of frequencies depending on geometry complexity, for instance; two for a beam and three for an arch $[37,38]$.

\subsubsection{Modal Damping}

Modal damping has been investigated as a possible damage sensitive feature due to the premise that cracking in a cross-section will increase internal friction, which in turn raises the value of the section's damping [39]. Similarly, Yamaguchi et al. [40] recently observed that damping ratios are particularly sensitive to the corrosion-induced damage of reinforced concrete beams. The drawback of this feature, however, has been highlighted by William \& Salawu [41] and Farrar et al. [42], who both concluded that measuring modal damping from vibration data produced large standard deviations that significantly impair their effectiveness as a reliable damage indicator. Damping levels in bridges are also nonlinearly influenced by vibration amplitude and operational effects [43]. Furthermore, damping levels may rise or fall depending on the damage type, for instance; cracking in reinforced concrete may increase damping due to increased internal friction and nonlinear behaviour, while the failure/removal of a truss element may reduce damping. Therefore, it is important to consider the expected deterioration when evaluating modal damping-based damage detection results.

\subsubsection{Mode Shapes}

Mode shapes are quite an advantageous condition assessment tool, being less influenced by environmental effects than frequencies [44], while also containing spatial information that can be used for damage localisation (Level 2 as per [29]). Many techniques have been developed over the years such as the Modal Assurance Criterion (MAC) by Allemang and Brown [45], which detects mode shape changes over the entire structure by taking advantage of the orthogonality of eigenvectors. Kim et al. [46] furthered the MAC in the development of the Coordinate Modal Assurance Criterion (COMAC) method, which uses modal node displacement to detect and locate damage. Equation (1) shows how COMAC can be applied to a node $i$, by measuring the normalised difference of mode shape vectors of the undamaged $\left(\varphi_{i, j}^{u}\right)$ and damaged $\left(\varphi_{i, j}^{d}\right)$ conditions. The application of MAC and COMAC in bridge structures by Salawu and Williams [47] found that the methods could detect most structural changes and locations, but also identified spurious damage. This was also observed when applied to beam structures, by Salgado [48], who showed that COMAC was prone to indicating false damage detections. COMAC remains a popular damage detection methodology across many engineering disciplines, with more recent, civil-based, applications of COMAC focusing on its incorporation with other methodologies to improve performance [49,50].

$$
\operatorname{COMAC}_{i, j}=\frac{\left[\sum_{j=1}^{m} \varphi_{i, j}^{u} \varphi_{i, j}^{d}\right]^{2}}{\sum_{j=1}^{m}\left(\varphi_{i, j}^{u}\right)^{2} \sum_{j=1}^{m}\left(\varphi_{i, j}^{d}\right)^{2}}
$$

\subsubsection{Modal Curvatures}

Pandey et al. [51] expanded mode shape monitoring theory to focus on modal curvatures, which are mode shapes' second derivative, in a technique known as the Modal Curvature Method (MCM). It utilises the relationship between curvature $\left(\varphi^{\prime \prime}\right)$ and flexural stiffness $(E I)$, as per Equation (2), with the premise that one can discern stiffness loss through increased modal curvature values. Equation (3) depicts how the MCM simply assesses the damaged curvature $\left(\varphi_{d, j}^{\prime \prime}\right)$ and undamaged curvature $\left(\varphi_{u, j}^{\prime \prime}\right)$ values to detect damage. This methodology demonstrated a high level of damage sensitivity and produced good results when tested [52]. Ho and Ewins [53] advanced the MCM 
by developing the Modal Curvature Squared Method, which amplifies curvature variations so that abnormal changes are clearly separated and more easily discerned.

The MCM also has some drawbacks; it requires many sensors to define higher modes and its performance is dependent on the number of modes considered [54]. Moreover, using vibration data to calculate curvatures inherently attains errors due to the application of the central difference approximation method to displacement mode shapes. This issue is further amplified by high-frequency noise that increases the variance of the extracted damage features [55], while using larger sampling signals to avoid noise can cause truncation error [56]. These calculation errors have been deemed unacceptable by some authors who compared the results with curvatures calculated from measured strain values [57]. Given such drawbacks, the MCM alone is not recommended for the purposes of damage identification, although its appropriate utilisation in conjunction with other sub-optimal modal parameters such as frequencies can enhance each other's credentials. This was demonstrated by Capecchi et al. [58], who enhanced natural frequency's damage sensitivity on an arch bridge using a course sensor distribution by taking advantage of MCM's sensitivity to local variations to overcome natural frequency's indeterminacy of damage localisation in symmetric structures.

$$
\begin{gathered}
\varphi^{\prime \prime}=\frac{M}{E I} \\
\Delta \varphi^{\prime \prime}=\sum_{j=1}^{m}\left(\varphi_{d, j}^{\prime \prime}-\varphi_{u, j}^{\prime \prime}\right)
\end{gathered}
$$

\subsubsection{Modal Strain Energy}

Modal curvatures form part of many other modal-based DSFs, such as the Damage Index Method (DIM) [59]. The DIM defines modal strain energy as the energy stored in a structure when it deforms in its mode shape pattern [54]. Damage is determined by observed reductions in modal strain, indicating that the structure is incapable of storing as much energy due to a loss of stiffness, as per Bernoulli-Euler beam theory.

Kim et al. [35] found that modal strains performed better than frequency-based damage indicators for damage localisation when assessed on Finite Element (FE) modelled beams. They also observed that modal strains could reasonably estimate crack size, making it possible to quantify damage. Yam et al. [60] observed that calculated displacement modes and strain modes for a tested plate structure were almost the same; however, strain modes exhibited a higher sensitivity to local structural change. Yam et al. also noted that the obtained strain response for higher modes was not very strong, which would indicate that their damage sensitivity is limited in these modes. As the DIM is based on modal curvatures, it therefore faces the same challenges as the MCM, as the central difference approximation method is required in most cases. Additionally, the DIM also employs curve fitting techniques between sensor locations to obtain continuous strain values; however, this can smooth-over and conceal local damage [54].

The DIM is presented in Equation (4), where $\beta_{i, j}$ represents the damage feature value for the $i$ th mode at location $j$. The values $\varphi^{u^{\prime \prime}}$ and $\varphi^{d^{\prime \prime}}$ are the curvatures of the undamaged and damaged mode shapes, respectively; $L$ is the element length; and variables $a$ and $b$ are the element limits.

$$
\beta_{i, j}=\frac{\left[\int_{a}^{b}\left(\varphi^{d^{\prime \prime}}\right)^{2} d x+\int_{0}^{L}\left(\varphi^{d^{\prime \prime}}\right)^{2} d x\right]}{\left[\int_{a}^{b}\left(\varphi^{u^{\prime \prime}}\right)^{2} d x+\int_{0}^{L}\left(\varphi^{u^{\prime \prime}}\right)^{2} d x\right]} \cdot \frac{\int_{0}^{L}\left(\varphi^{u^{\prime \prime}}\right) d x}{\int_{0}^{L}\left(\varphi^{d^{\prime \prime}}\right) d x}
$$

The DIM was advanced by Cornwell et al. [61] to allow the application to be extended to 2-Dimensional (2-D) bending structures and again by Duffey et al. [62] for structures exhibiting axial and torsional responses, although these methods require many more sensors and deviate from the original curvature-flexural stiffness relationship (Equation (2)). 


\subsubsection{Modal Flexibility}

Modal flexibility is another popular modal parameter that has been used for structural damage detection. First proposed by Pandey \& Biswas [63] and subsequently applied to bridges by Toksoy \& Aktan [64], the modal flexibility method (MFM) defines the flexibility matrix as the inverse of the stiffness matrix (see Equation (5)). It is deemed that this format can be adequately defined with fewer modes than is required for stiffness matrices. This allows for greater damage sensitivity to be attributed to the more easily extracted lower modes. Furthermore, the MFM combines the information of many frequency modes into a single damage feature, which increases damage sensitivity. Wang et al. [65] confirmed that MFM advanced damage sensitivity when compared to other modal-based damage indicators; while Shih et al. [66] demonstrated MFM's damage localisation capabilities in beam and plate structures when tested via a dynamic computer simulation.

One reason for MFM's decent level of performance stems from its use of mass-normalised mode shapes, which allow the flexibility matrix to portray the displacement pattern of the structure per unit force applied. This allows damage events (increases in flexibility/decreases in stiffness) to be assessed uniformly throughout the structure and also enhances localisation. However, MFM's performance suffers when subjected to ambient or unknown conditions, as mass-normalised mode shapes require the load effect to be known in advance. Some studies have attempted to mass-normalise dynamic mode shapes extracted from ambient vibration in an effort to utilise MFM's superior damage detection and localisation sensitivity $[67,68]$, but these methods carry a considerable level of uncertainty through having no prior knowledge of the force input data.

Equation (5) portrays the stiffness/flexibility relationship, where $\{f\}$ and $\{y\}$ are the load vector and displacement vector, respectively, and $[k]$ and $[G]$ are the stiffness matrix and flexibility matrix, respectively, that have been mass normalised. Equation (6) furthers portrays how the flexibility matrix is computed, where $[\psi]$ is the mass-normalised mode shape matrix, $[\Lambda]$ is the measured eigenvalue matrix, $\omega_{i}$ is the $i$ th modal frequency, and $\{\psi\}_{i}$ is the $i$ th mode shape vector.

$$
\begin{gathered}
\{f\}=[k]\{y\} \rightarrow\{y\}=[k]^{-1}\{f\}=[G]\{f\} \\
{[G] \approx[\psi][\Lambda]^{-1}[\psi]^{T} \approx \sum_{i=1}^{m} \frac{1}{\omega_{i}^{2}}\{\psi\}_{i}\{\psi\}_{i}^{T}}
\end{gathered}
$$

Further examples of modal flexibility used in Structural Health Monitoring (SHM can be found in Zhang \& Aktan [69], who incorporated the use of the modal curvature method to monitor changes in flexibility. They proposed that damage events that reduce stiffness and increase flexibility would also increase local curvature in the same location, and by combining both methods, damage sensitivity would be increased. Lu et al. [70] tested the MFM and its curvature hybrid technique on a beam and determined that modal flexibility is very sensitive to local damage; however, in cases where numerous damage scenarios were introduced, the resulting flexibility peaks merged together, making localisation difficult. Furthermore, they noted that multiple damage events of varying magnitudes resulted in flexibility changes in locations other than the damage location. However, they found that the hybrid flexibility curvature method produced superior results in locating closely distributed damage and discerning between different magnitudes of damage events.

\subsubsection{Summation of Modal-Based Damage Sensitive Features}

The present section has detailed the development and varied performance results of numerous modal-based DSFs used in a bridge-related SHM. Many comparative studies have been conducted to assess the aforementioned modal parameters against each other, such as Talebinejad et al. [71], who applied COMAC, DIM, MCM, and MFM to a FE model of a cable-stayed bridge subjected to varying degrees of excitation and noise. It was found that only large damage events were detected, as noise contamination reduced damage sensitivity. Ndambi et al. [72] performed laboratory tests on RC beams using frequencies, MAC, COMAC, MFM, and DIM. They found that COMAC and DIM 
performed well in regard to damage localisation, although damage development was not incrementally detected correctly, meaning that the quantification of damage was not possible.

Cruz \& Salgado [73] also investigated mode shapes, MCM, \& MFM using a simulated model of a composite bridge and real vibration data from a progressive damage test. For the simulated model, all assessed parameters detected and located damage when no noise was present. When noise was added, damage detection and localisation performance diminished considerably for all DSFs. For the real data, it was noted that clear changes were evident in higher modes when damage was introduced; however, lower modes did not exhibit much variation despite the presence of severe damage. It was noted that MCM and MFM demonstrated the greatest detection and localisation capabilities. Fan \& Qiao [74] echoed many of these findings in their assessment of frequencies, mode shapes, MCM, and DIM, with superior damage sensitivity observed for higher modes, particularly for modal curvature-based parameters, and a diminished performance overall when subjected to noise. They concluded that many of the assessed damage features were not reliable for damage detection and that many spatial parameters produced only rough estimations of damage location in the absence of advanced signal processing techniques.

In summation, the modal-based DSFs evaluated within have been shown to be susceptible to noise contamination and perform inconsistently when comparatively assessed in groups. Also, the assumption of linear stationary structural vibration response made by most frequency domain transforms used to obtain modal-based DSFs may not always be suited to real-World applications, as vehicle-induced excitations on damaged bridges can be highly non-stationary in nature. Having said this, natural frequencies can provide a simple high-level assessment of structures of regular geometry, while mode shapes and their derivatives can deliver useful spatial information when provided with sufficient sensor numbers and low noise levels.

\subsection{Problematic Effects of Environmental \& Operational Conditions}

External conditions affect changes to a bridge's stiffness and mass that in turn vary its modal parameters. Temperature causes expansion and contraction, resulting in observed daily frequency shifts of $5 \%$ and seasonal shifts of well over $10 \%$ due to temperature fluctuations [75-78]. Moisture content can also alter the temperature's effect, which Peeters \& De Roeck's [75] discovered when a bi-linear distribution of modal frequencies was observed for the Z-24 Bridge centred around freezing point; the cause of which was attributed to the freezing moisture content in the bridge deck and supports, which contributed to the global stiffness of the structure.

Generally, an increase in temperature will cause modal frequencies to drop, with flexural modes being more sensitive than torsional modes [79]. Changes in frequency due to temperature can often be mistaken for structural damage $[80,81]$ and, in some cases, can also mask true damage events, as Farrar et al. [82] discovered when investigating a bridge girder subjected to incrementally induced damage events. The expectations of the assessment were that the inflicted damage would reduce the girder's stiffness and thus reduce its natural frequencies. However, the actual observed results did not match expectations; instead, the girder's natural frequency rose for the first two damage scenarios, before falling. It was later discovered that the ambient temperature in the laboratory caused the initial increase in the girder's frequency.

Daily operational variability can be a more dominant driver of frequency fluctuation than daily environmental variability [83], with over $5 \%$ of daily frequency fluctuation being due to the operational conditions observed [84]. Kim et al. [85] observed that mass variations induced by traffic loading affect shorter span bridges much more than stiffness variations induced by environmental conditions, as shorter span bridges are less susceptible to ambient excitations. In another study, Kim et al. [86] demonstrated that natural frequency variations due to traffic loads were almost negligible for middle to long span bridges. This is due to the mass ratio between the overall bridge structure and the vehicle, and implies that heavier bridges are less affected by variations in mass, which has been reiterated by numerous authors [87-90]. 
Other concerns regarding operational conditions relate to their fatigue inducing stress cycles in welded connections. Alcover et al. [91] highlighted that this issue is of particular interest in orthotropic steel decks, where their complex geometry coupled with the stochastic nature of traffic loads result in complex stress fields. Song and Ding [92] observed a highly linear correlation between the traffic volume and number of stress cycles in orthotropic steel deck joints, especially for rib-to-deck welded joints. A similar correlation between stress amplitude and ambient temperature was also observed and attributed to temperature-induced changes in asphalt material properties.

Traffic-induced modal variation can be considered to occur in both static and dynamic form. Static variations can be directly related to mass; however, traffic-induced dynamic variation has been shown to be nonlinear and can decrease with an increasing load effect [93]. This further complicates the vibration-based monitoring of in-service bridges, as perceived changes in a bridge's modal parameters may actually be the interaction response of a healthy bridge with a passing vehicle [85]. This relationship is difficult to discern, as it is based on a number of variable factors such as, vehicle weight, velocity, number of vehicles, bridge weight, and temperature. Furthermore, Brady et al. [94] observed that the amplification of frequency response due to a single passing vehicle is considerably more than for two vehicles simultaneously passing in opposite directions, thereby indicating the influence of vehicle direction. In a subsequent study, O'Brien et al. [95] allocated the cause of this phenomenon to single vehicle crossing behaviour mirroring a bridge's first mode shape pattern, thus amplifying the dynamic response. Other, more complex bridge traffic crossing events, where vehicle locations and velocities are such that they induce dynamic amplification, are much less probable.

Considering the number, complexity, and uniqueness of the environmental and operational conditions that affect the dynamic response of an individual bridge, it is evident that a perfect multivariate, nonlinear model is unattainable for every bridge. Therefore, damage detection methodologies should be designed to either compensate for or eliminate the most prevailing effects of these variables. It is clear that the failure to remove these influences will result in the DSFs being sensitive to more than just damage.

\section{Advancements and Alternatives to Modal-Based Damage Identification}

A number of shortcomings relating to modal-based DSFs were highlighted within the previous section regarding their consistency, robustness, and suitability for mass application to bridge networks. For purposes of clarity, the discussed challenges and shortcomings of traditional modal-based DSFs can be separated into three categories, as show below. Recent advancements and novel alternatives to these three areas of contention form the discussion basis of the present section.

1. Problematic influence of environmental \& operational effects;

2. Inefficient utilization of machine learning algorithms for damage detection;

3. Over-reliance on modal-based damage sensitive features.

\subsection{Advancements to Environmental \& Operational Challenges}

Environmental and operational conditions can significantly alter a bridge's modal parameters, to a point where damage events can be masked. Most problematic of such variables is temperature [89], with many techniques having been developed over the years dedicated to estimating and mitigating its influence; generally through various data normalisation techniques, see Sohn [90] and Xia et al. [96]. The present section details techniques that can be employed when environmental and operational data is available (regression models) and when it is not (pattern recognition). Additional advancements in operational specific challenges such as real-time traffic estimation and the non-stationarity of traffic-induced vibration are also covered within. 


\subsubsection{Regression Models}

To accurately estimate temperature influence, it must be recorded with the intention to utilise both its spatial and temporal evolution. Bridges subjected to large daily temperature variations will exhibit greater spatial thermal gradients, while larger bridges will take longer to respond to temperature fluctuations and will thus have greater temporal thermal gradients.

While spatial thermal gradients can be determined with additional thermocouples as shown by Cornwell et al. [77], temporal thermal gradients require the implementation of a regression model, such as least squares, that fits a linear equation to the variable relationship. Multi-linear regression models provide a suitable option for most bridge types and environments, as shift changes in frequency due to sub-zero temperatures can be modelled. Generally, a regression error value of circa $5 \%$ is used to reduce the effect of erroneous data, as seen in [97]. Dervilis et al. [98] employed a multivariate linear regression method called the Least Trimmed Square (LTS) estimator, which is fashioned upon the popular least squares approach, but incorporates an initial screening procedure called a Concentration step (C-step) [99]. The C-step is an iterative process that finds the minimum determinate of a number of data subsets, with the aim of identifying the sub-scatter of highest density that is most representative of the data. This allows for erroneous data points or outliers to be removed before the linear regression model is fitted. In this way, the LTS is less sensitive to local variations and dubious data. Vanlanduit et al. [100] also employed the same technique to increase their regression model's robustness when used in conjunction with Single Value Decomposition (SVD) for damage detection. Their subsequent comparison with standard linear regression techniques showed that the inclusion of a screening stage such as the C-step improves the accuracy of the model and subsequent damage detection.

More complex regression models may incorporate a polynomial curved fit as per Ding and Li [101], whose polynomial regression model exhibited an excellent capability in regard to mapping daily averaged output-only modal frequency variability using daily averaged temperature fluctuations in a long-span suspension bridge. The authors used daily averaged values to reduce the effect of random modal variations that arise from the modal identification algorithm being subjected to non-stationary loading. Their success could also be partly attributed to their utilisation of the Iterative Windowed Curve-fitting Method (IWCM), instead of the standard peak peaking method for modal frequency identification. The IWCM is a frequency domain curve fitting technique that overcomes spectral bias errors that occur in standard frequency domain analyses, caused by the attenuation of values around spectral peaks. It achieves this by applying the same window function used on the time domain data to the resulting frequency domain data, as per Macdonald [102].

\subsubsection{Pattern Recognition Methods}

One drawback of many data normalisation techniques is the requirement of environmental or operational data which may not be available. In this case, Principle Component Analysis (PCA) may potentially be employed by considering the first principle components as representative of environmental-induced variation. If these principle components are removed, one should be left with a dataset representing the true behaviour of only the bridge. Yan et al. [103] implemented this technique using simulated linear data and, later, pricewise linear data [104], by increasing the PCA model order to account for the nonlinear response to sub-zero temperatures. The premise of this technique lies in utilising PCA's dimensionality reduction capabilities in a novel way. It is considered that environmental variables (temperature, wind, humidity, water level, etc.) or operational variables (vehicle speed and mass distribution) will each increase the dimensionality of the measured vibration signal. The number of dimensions can be identified via PCA by counting the non-zero eigenvalues of the covariance matrix [105], which represent the variables' unique, shared erroneous variance [106]. Once identified, one can remove the environmental and operational influences, without the need to physically measure them. This method may be slightly subjective and has been shown to be sensitive to noise, but can be considered as an alternative for linear problems when no recorded environmental data is available. 
Similar to PCA, Factor Analysis (FA) has been shown to reveal linear dependencies and correlations between multiple variables in a dataset [107], for example, natural frequencies. However, instead of directly measuring the overall variance like PCA, FA assumes that there are a smaller number of underlying, unobservable factors called "latent common factors" ([ $\xi]$ in Equation (7)) which are assumed to be independent with zero mean and unit variance that describe the variables' influence on the data. The number of latent common factors is limited in number to the number of variables in $[X]$, and each one attains a "factor load" $[\Lambda]$ which quantifies their influence and allows for their removal. Each factor load is equivalent to a principal component multiplied by the square root of the corresponding singular value. Once the latent common factors $[\xi]$ and factor loads $[\Lambda]$ are removed from the measured variables $[X]$, the remaining data are known as "unique factors" $[\varepsilon]$, which should be a diagonal matrix of independent variables that are unaffected by environmental and operational effects, and as such, can be used for damage detection purposes [108]. As this is a supervised machine learning methodology, sufficient training data is required for a successful application that captures all expected daily and seasonal variations. Deraemaeker et al. [109] successfully implemented this technique in their assessment of output-only vibration-based damage detection under changing environmental conditions.

$$
[X]=[\Lambda][\xi]+[\varepsilon]
$$

Lämsä \& Raiko [110] advanced the theory of FA in SHM to cater for non-linearities by incorporating linear FA into a Neural Network $(\mathrm{NN})$ type format that allows multiple linear factor models within each measured variable. Both Lämsä \& Raiko [110] and Kulla [108] assessed non-linear FA on the Z-24 Bridge and concluded that it is a feasible damage detection methodology and that it is less susceptible to over-fitting-related issues when compared to other non-linear methods. However, it should be noted that although FA assumes that the latent common factors are independent of each other and Gaussian in nature, this is not always the case in reality, as it is known that temperature and humidity are correlated and not all environmental and operational variables are normally distributed.

In the case of non-linear environmental effects, a Non-Linear Principle Component Analysis (NLPCA) may be employed, of which there are numerous variations. Hsu and Loh [111] implemented a NLPCA method based upon the use of an Auto-Associative Neural Network (AANN), originally developed by Kramer [112], which uses a five-layer mapping-network whose output pattern is identical to its input pattern. The five layers consist of an input layer of measured variables, a sigmoid nodal mapping layer that projects the inputs onto the following feature-space bottleneck layer of linear transfer nodes which act as the nonlinear principle components, followed by a second sigmoid de-mapping layer that finally projects the non-linear principle components back into their original form. Once trained, the AANN is validated with undamaged data, resulting in Gaussian residual errors which can be used to determine a damage threshold for subsequent unknown input measurements. The authors tested the method on a synthetic bridge model considering nonlinear environmental effects (temperature gradient and frozen supports) and modal identified stiffness's as inputs. They found that the method was capable of detecting and quantifying introduced damage, without the need to measure environmental factors.

Another method of NLPCA is Kernel Principle Component Analysis (KPCA), which incorporates a kernel function that non-linearly maps the measured variables into a higher-dimensional linear space where normal PCA can be conducted. The kernel function describes the distribution of the data using Gaussian or extreme value distribution parameters. The successful application of KPCA was carried out by Nguyen et al. [113], who used a Gaussian kernel on modal parameters obtained from a progressive damage test conducted on the Champangshiehl Bridge in Luxembourg under varying environmental and soil effects. Oh et al. [114] implemented KPCA on recorded hanger tensions from the in-service Yeongjong Grand Bridge in Seoul, using a Gaussian kernel to characterise the nonlinear relationship between the hanger tensions and the unmeasured environmental and operational conditions, prior to using extreme value statistics for successful abnormality identification. In a comparative study of PCA-based algorithms for damage detection under nonlinear conditions, 
Santos et al. $[115,116]$ concluded that KPCA-based algorithms produced fewer false-positives, without significantly increasing false-negative detections when compared to standard PCA and NLPCA.

The specification of two parameters is necessary for KPCA; the first is the kernel width, which represents the standard deviation of the kernel, while the second is the number of principle components extracted. These parameters have a profound effect on the performance, as the number of principal components is correlated to the number of environmental and operational parameters and the overall variance of the data. Recently, Reynders et al. [117] proposed a methodology of automatically selecting these two parameters through first employing Shannon's information entropy to maximize the matrix of mapped output correlations, as per Widjaja et al. [118], to attain an accurate kernel width value, before selecting the number of principle components that represent almost all of the environmental and operational variability.

Additional instances of neural network-based algorithms being successfully applied to bridges under variable environmental conditions include Li et al.'s [119] use of NN's to assess modal parameters under varying wind and temperature effects. They concluded that natural frequencies and damping ratios are dramatically affected by wind and temperature, while mode-shape sensitivity was insignificant. Jin et al. [120] analysed a composite steel girder bridge (Meriden Bridge) to determine the frequency/temperature relationship and to attempt to detect damage under severe temperature fluctuations and operational conditions. They combined time-series analysis with an Autoregressive Neural Network (ANN). The frequency/temperature relationship for the first seven modes was analyzed using an auto-correlation function and a cross-correlation function, which showed that all seven modes attain very similar relationships with temperature. This allowed the authors to reduce the number of input variables required to train the ANN for the purposes of structural damage detection. Comparative results with a multi-linear regression model showed that the ANN prediction method produced fewer error values overall than the multi-linear regression model.

Jin et al. [121] conducted further work on the Meriden Bridge in a study that aimed to model the frequency-temperature relationship using an extended Kalman filter for NN learning, which attains a superior convergence speed and success than other common NN training algorithms, such as back propagation. The extended Kalman filter works as a second-order algorithm for recursive state estimation in nonlinear dynamic systems, and as $\mathrm{NN}$ training can be considered as a nonlinear estimation problem, the two work together in synergy. Comparison results against a multi-linear regression model produced fewer error vales and demonstrated the potential for real-time monitoring applications.

\subsubsection{Advancements to Operational Specific Challenges}

An accurate determination of environmental and operational conditions is an important aspect of bridge SHM and can require substantial instrumentation, particularly for operational specific variables. Recently, Fiber Bragg Grated (FBG) sensors have be employed as strain and temperature sensors, as Kaloop et al. [122] demonstrated on the Fu-Sui Bridge in China, who obtained temperature data and traffic volume in real-time. For temperature measurements, the dynamic strain histories were passed through a smoothing low-pass moving average filter, which produces low frequency strain evolution that is directly correlated with recorded temperatures. For traffic volume measurements, results from previous findings $[123,124]$ showed that traffic-induced strain fluctuations were shown to be identifiable as peak impulses in dynamic strain histories. Therefore, Kaloop et al. set out to isolate the traffic-induced strain fluctuations from the FBG sensors by first applying a wavelet decomposition filter to the original strain measurements to enhance the resolution. Then, a simple low-pass moving average filter was applied to smooth out the traffic impulses. Vehicle passages were then identified by extracting the impulses within the residual leftover between the filtered and smoothed strains. The vehicle type was determined based on the thresholds applied to the strain impulses. Over the course of the monitoring campaign, the traffic volume of the Fu-Sui Bridge was deemed to have increased by $55 \%$. 
The utilization of the Hilbert-Huang Transformation's (HHT) [125] ability to decompose non-stationary and non-linear signals into instantaneous frequency and energy has recently seen a rise in popularity, with Chen et al. [126] compiling a comprehensive review on its application in SHM. The HHT is a two-step process that firstly consists of a decomposition stage called Empirical Mode Decomposition (EMD) [125], whereby the raw vibration signal is transformed into multiple vibration signals of equal duration known as Intrinsic Mode Functions (IMFs). EMD employs a "shifting process" to separate time series composed of frequencies in decreasing order, with the first IMF generally composed of high frequency noise that can be rejected. The remaining IMFs should portray the dominant frequencies of the system, such as instantaneous modal frequencies. Unlike Fourier-based transformations, EMD's empirical methodology allows the nonlinear characteristics of the raw signal to be maintained, which is beneficial for the assessment of traffic-induced vibration.

In fact, the utilization of the EMDs alone can yield identification of structural damage based on changes to its intrinsic mode functions' curvature [127]. Additionally, many SHM applications of the HHT have been conducted on data obtained from numerical models [128] and laboratory-based experiments [129]. However, recent research by Moughty \& Casas [130] has focused on the potential of using the HHT to detect early stage damage in bridges subjected to operational loading. The premise of the application of HHT in this way stems from the fact that the majority of bridges are designed to behave linear-elastically under operational design loads, which implies that healthy bridges subjected to normal operational conditions should produce a nonlinear, but stationary dynamic response. However, the presence of damage will induce nonlinear-inelastic structural behavior, resulting in signal non-stationarity that should be identifiable in the HHT spectrum. The SHM benefit of this method over other frequency domain transformations that assume stationarity is that earlier damage detection may be possible, as vehicle loading may momentarily induce a modal frequency change (non-stationarity), which would be otherwise masked in Fourier type transforms.

\subsection{Advancements to Machine Learning Methodologies for Damage Indentification}

As detailed for most modal-based damage features, their drawback predominantly stems from their susceptibility to environmental and operational influences; however, given the recent advancements in removing environmental and operational influences, as detailed in Section 3.1, more reliable damage feature sets can now be extracted. The final step is to implement a suitable outlier detection algorithm to separate damaged parameters from those of which are undamaged.

Mahalanobis Squared-Distance (MSD) [131] is a common Gaussian-based multivariate outlier detection technique used in SHM that's based on detecting divergences from the mean and covariance matrix of a training dataset. The MSD is determined as per Equation (8), where $\{X\}_{\zeta}$ is the potential outlier, $\{\bar{X}\}$ is the mean of the training data, and $[\Sigma]$ is the covariance matrix of the training data. The success of the MSD is dependent on clean Gaussian distributed data of a sufficient sample size and/or number of variables, so that a reliable threshold value can be determined.

$$
D_{\zeta}=\left(\{X\}_{\zeta}-\{\bar{X}\}\right)^{T}[\Sigma]^{-1}\left(\{X\}_{\zeta}-\{\bar{X}\}\right)
$$

An example of the MSD in use in bridge SHM can be seen in Chang \& Kim's [132] modal comparative study, where multiple damage features (frequencies, MAC, COMAC. and modal damping) were extracted for the first four modes from vibration data induced by a moving vehicle on a steel truss bridge subjected to four progressively induced damage scenarios. Initially, each feature was assessed individually per mode using the MSD. This provided mixed results, with damping ratios exhibiting almost no discernible damage sensitivity for any mode or damage scenario, while the other features managed slightly better, but exhibited little consistently across all modes.

Chang \& Kim [132] went on to demonstrate how the results can improve if a number of modal parameters are considered simultaneously per mode, and even further so if combined across all four modes. This method of feature stacking increases the dimensionality of the damage feature 
assessed and allows the utilisation of MSD's multivariate capacity. However, to successfully use MSD in this way requires a standardisation of the various damage features so that their covariance matrices are comparable in scale. For this, the authors used an adapted MSD algorithm known as the Mahalanobis-Taguchi System (MTS) [133]. The MTS is an efficient supervised learning method that sorts and removes variables in a multidimensional pattern recognition problem by using signal-to-noise ratios and orthogonal arrays to quantify each variable's contribution. This can be particularly beneficial when using multiple modal parameters for damage detection that exhibit inconsistent damage sensitivity when individually assessed. Unknown or damaged data is first normalised using the healthy data's mean and standard deviation. Although it has not seen much use in the SHM field as of yet, it has been widely used in medical diagnosis studies that consider a large number of variables. One comparative study [134] used a cancer diagnosis problem to assess MTS's performance to that of a Neural Network's and found that the MTS classification accuracy was higher than that of the NN overall, whilst also being much faster and having identified three variables for removal.

A further advancement to the standard MSD is to pair it with the Minimum Covariance Determinate (MCD) estimator [99] that mitigates the uncertainty regarding the presence of outliers in training data. It achieves this by using an iterative process of subdividing the data into two groups and calculating their determinate in order to refocus the covariance matrix on the mode of the total dataset instead of the mean. The assumption of Gaussian distribution still holds for the data, but allows outliers to be ignored. This is particularly useful in damage detection scenarios as the inclusion of outliers in training data can mask the occurrence of damage events. Dervilis et al. [98] successfully employed the MSD in conjunction with the MCD to separate environmental- and operational-induced variations from real damage on the Z-24 Bridge.

Another robust geometry-based outlier detection technique is the Minimum Volume Enclosing Ellipsoid (MVEE) [135]. The MVEE algorithm's aim is to determine the ellipsoid of minimum volume that will enclose the data. It is based on convex optimisation via conditional gradient estimation that results in the data being surrounded by an elliptical boundary whose centre vector is determined by that which will produce the minimum volume. It is an iterative process that involves varying the centre location $\{c\}$ and symmetric matrix $[A]$ to attain a volume $E$, as per Equation (9). The volume is subsequently minimised via Equation (10), where $u_{0}$ is the volume of a unit hypersphere.

$$
\begin{gathered}
E=\left(\{X\} \in R(\{x\}-\{c\})^{T}[A](\{x\}-\{c\}) \leq 1\right) \\
\operatorname{vol}(E)=\frac{u_{0}}{\sqrt{\operatorname{det}([A])}}
\end{gathered}
$$

In terms of the performance assessment of the above algorithms, there have been a few assessment reviews conducted. Dervilis et al. [136] assessed the performance of the MSD, MCD, and MVEE algorithms on the Z-24 Bridge that included environmental variations. Their study showed that the MCD outperformed the MSD in terms of damage sensitivity and resolution; however, the MVEE produced significantly better results than both. Figueiredo et al. [137] used AR model parameters to review the performance of a number of popular machine learning algorithms such as, MSD, Factor Analysis (FA), Singular Value Decomposition (SVD), and Auto-Associative Neural Network (AANN). From this, it was deemed that MSD gave the best results in terms of performance, speed, and simplicity.

\subsection{Non-Modal Damage Sensitive Features}

Due to many modal-based DSFs' sensitivity to environmental and operational conditions, in addition to their various extraction challenges, there has been an increase in damage detection and identification assessments that utilise non-modal-based DSFs. The majority of these non-modal features can be subdivided into two classes; vibration-based and time-series-based, some of which are highlighted herein. 


\subsubsection{Vibration Based Damage Sensitive Features}

Vibration-based DSFs are parameters extracted from raw accelerations that generally measure a variant of vibration energy or another vibration property. The premise of this lies in the fact that as the bridge is damaged, it needs to resist external loading using more kinetic energy as it attains less potential energy.

Moughty \& Casas [138] assessed the damage sensitivity of a number of vibration parameters extracted from a progressive damage test on the S101 Bridge in Austria subjected to ambient excitation [139]. The parameters assessed were: Max Peak-to-Peak Acceleration; Sustained Maximum Acceleration [140]; Mean Period [141]; Mean Frequency; Cumulative Absolute Velocity [142]; Arias Intensity [143]; Destructive Potential Factor [144]; and Vibration Intensity (in Vibrars) [145]. The authors employed the MSD outlier detection algorithm in conjunction with the MCD estimator to mitigate the uncertainties regarding sources of ambient vibration and to ensure that the training data were not corrupted by outliers. The results showed that vibration energy-based parameters exhibit considerable damage sensitivity, which can be further amplified through the incorporation of a frequency-based denominator, as in the case of Destructive Potential Factor and Vibration Intensity (in Vibrars).

In the study by Meixedo et al. [146], damage indicators were defined and tested based on the deck accelerations under action of operation forces designed as moving loads in a 2-D FE model. A parametric study assessed a number of vibration parameters such as the maximum peak amplitude, minimum peak amplitude, standard deviation, and sum of squared differences between baseline acceleration and damaged acceleration. The results showed that many of the vibration-based DSFs possess strong damage sensitivity and the potential for damage localisation and quantification. Kaloop \& Hu [147] assessed a number of pattern recognition-based damage identification algorithms using vibration data from the Yonghe Bridge. They determined that acceleration amplitude was quite responsive to damage and it was concluded that this method had the potential for online damage detection due to its ease of application. This conclusion echoed similar findings by Casas \& Rodrigues [148], who observed a correlation between peak acceleration amplitude and the existence of damage in a group of assessed bridges.

Santos et al. [149] implemented a baseline-free method of damage detection using symbolic data analysis (SDA) to reduce raw vibration data collected from the Samora Machel Bridge into smaller representative sets of statistical significant components such as interquartile intervals. The authors observed that the interquartile intervals attained enough damage sensitivity to accurately detect changes in the bridge condition over time. The dynamic cloud clustering algorithm was employed in the study, which is a more efficient adaptation of the popular k-means clustering algorithm; however, due to the methodology's tendency to converge to local minima, a cluster validation step was introduced to ensure robustness. It consists of computing a set of indices for each identified cluster that describes their density and location. Subsequent identified clusters are then compared to the indices obtained to determine the most likely number of clusters.

Limongelli $[150,151]$ proposed a non-modal based damage detection technique, known as the Interpolation Damage Detection Method (IDDM). It operates by defining a damage index in terms of expected, or reference, deformed shapes calculated from Frequency Response Functions (FRFs) to monitor bridge condition. By using deformed shapes as a damage indicator, one can take advantage of concentrated vibration amplitude irregularities to detect and locate damage, as other authors have successfully achieved [152,153], while others focused on the variation of deformed shape curvatures to detect damage [154-156], the latter using a cubic polynomial to represent curvatures. Dilena et al. [157] extended this concept through the incorporation of a cubic polynomial spline interpolation function, applied to the deformed shapes to extenuate deformations. This method allows spatial abnormalities to be detected without requiring a curvature calculation, which would innately contain errors via the double differentiation process. Higher interpolation errors indicate a greater likelihood of damage, which requires the IDDM to apply a probabilistic means of damage 
determination so that only interpolation errors that are greater than a pre-determined threshold are deemed as probable damage events.

Dilena et al. [157] assessed the IDDM's performance against the MCM on a single span RC bridge under forced harmonic vibration subjected to incremental damage at various locations. The results showed that the IDDM is consistently capable of detecting, locating, and tracking the evolution of damage; however, its performance is dependent on the threshold value chosen and on sensor distribution. When compared to the MCM results, the IDDM fairs quite well. The MCM demonstrated good sensitivity to damage for the first two vibration modes, but became less accurate thereafter. This is most probably due to the requirement of a denser array of sensors for accurate modal curvatures at higher modes. The IDDM requires fewer sensors than the MCM by reliably detecting and locating damage. However, IDDM assumes that all sources of vibration will equally cause all locations to produce the same variation in interpolation error, which may not be suitable for all bridge applications.

\subsubsection{Time Series Based Damage Sensitive Features}

Auto-Regressive (AR) models and their common adaptations (ARMA and ARMAX) are very versatile tools that can be used instead of modal parameters to extract DSFs such as residual errors or AR model parameters, provided that a suitable model order is selected [158]. Given the present paper's aim and scope, the reader is advised to inquire the following publications for a more detailed account of AR type models' theoretical base $[159,160]$. However, it is important to note that their damage sensitivity arises from the assumption of stationarity, which allows for the detection of nonlinear behaviour in the vibration data by inducing changes in the residual errors and/or model parameters [161]. Residual errors are assumed to be Gaussian and are assessed using Gaussian-based outlier detection techniques such as MSD [162,163] or Gaussian mixture models [164]. Multiple sensor locations may be used for the purposes of damage localisation; however, prior to fitting the models, the sensor data must be normalised in order to remove variable external condition influences such as traffic and temperature, so that all signals have similar statistical characteristics. The common method of normalising sensor data for the purpose of AR model fitting is to apply Equation (11) to the sensor data, where the normalised data $\left(x_{\text {norm }}\right)$ is determined from the time series' mean $\left(\mu_{i}\right)$ and standard deviation $\left(\sigma_{i}\right)$ applied to each time step $\left(x_{i}(t)\right)$. This also produces a much more stationary signal that is suitable for AR type models.

$$
x_{\text {norm }}=\frac{x_{i}(t)-\mu_{i}}{\sigma_{i}}
$$

Mei \& Gül [165] developed a novel ARMAX model that can identify changes in both stiffness and mass separately using output-only data by applying the ARMAX model to the standard equation of motion. Two sets of ARMAX models were constructed for the verification process; one for a baseline state and another for the damaged state. The percentage differences of the two model's ARMAX coefficients are taken as damage features. Their methodology was verified by two numerical models; one consisting of a 4-DOF mass/spring system, and the other being the IASC-ASCE benchmark problem [166] of a multi-story structure with incremental damage applied. The results show that the proposed methodology could consistently detect, locate, and quantify changes in mass and stiffness, independently of one another. This is due to the fact that the mass and stiffness are separated into the denominator and the numerator in the developed model. However, a real-world application is required to determine its true robustness, particularly under varying environmental conditions.

Chatzi \& Spiridonakos [167] proposed another time-series-based damage detection model that incorporates environmental data and a full numerical model of the structure that extrapolates expected behaviour so that the assessed vibration response can be deemed normal or abnormal. The method is known as Polynomial Chaos Nonlinear Auto-Regressive with eXogenous input (PC-NARX) [168]. The Polynomial Chaos Expansion (PCE) allows the parameters to be characterised as random variables, for example; acceleration time histories are represented by their Probability Density Function (PDF) parameters, so that measured vibration data can be handled as a set of random variables. This 
speeds up subsequent runtimes considerably, as large acceleration data sets can be reduced to a few representative values. Likewise, this methodology caters for the inclusion of structural uncertainty, by allowing structural properties and dimensions to be included in the numerical model as PDF variables. The PC-NARX then predicts the dynamic response of a structure through a process called meta-modelling. Validation of the PC-NARX was conducted by comparing its predictions and simulation speed to that of an FE model. A normalised one-step-ahead prediction error of $0.0074 \%$ was obtained by PC-NARX with a simulation speed 100 times faster than that of the FE model. The ability of the PC-NARX to accurately predict the dynamic response of a structure under varying environmental conditions implies that it should also be able to discern damage events by monitoring the magnitude of its prediction errors, which are assumed to be Gaussian.

Cross et al. $[169,170]$ introduced the use of cointegration into SHM that can be used to remove the environmental and operational effects from non-stationary raw time series data for the purposes of damage detection. Cointegration is determined when two or more non-stationary time series form a stationary process are linearly combined, with the stipulation that both original time series must share the same degree of non-stationarity to begin with. It is commonly used in econometric analysis; however, it can also be applied to multi-sensor data in a SHM context. A maximum likelihood approach known as the Johansen Procedure [171] is used to identify the most stationary linear combination of the non-stationary variables possible. The resulting stationary process is referred to as a residual and will remain stationary, regardless of environmental conditions, until the linear relationship between the two cointegrated variables changes, which will induce a non-stationary change to the residual and may indicate the presence of damage. The methodology has recently been advanced to cater for non-linear cointegration through the use of Gaussian process regression as a cointegrating function that builds non-linear cointegrating relationships between variables [172]. The nonlinear adaptation was applied to real data from the Z-24 Bridge in Switzerland and successfully eliminated environmental and operational effects without the need to measure them, while also demonstrating considerable damage sensitivity.

\section{Summary}

The present paper began by detailing the development and application of a wide array of modal-based DSFs that have become well known in SHM literature. These DSFs are supported by a well-established theoretical base, but their application to real bridge structures have produced inconsistent comparative results and highlighted a susceptibility to noise, particularly for the more damage sensitive higher modes. Additionally, the assumption of linear stationary structural vibration response made by common frequency domain transformations used to obtain modal-based DSFs may not always be suited to real-World applications. The discussed shortcomings of modal-based DSFs in SHM were characterised into three categories as shown below, which formed the subject topics of the remaining sections of this paper.

1. Problematic influence of environmental \& operational effects;

2. Inefficient utilization of machine learning algorithms for damage detection;

3. Over-reliance on modal-based damage sensitive features.

Much of the problematic influence of environmental variations on modal-based DSFs' performance has been shown to be mitigated through the utilisation of carefully chosen multivariate regression models or the suitable application of pattern recognition algorithms. Simple linear regression models are not appropriate for locations of large temperature fluctuations and humid conditions, as freezing moisture content in bridge decks produces a nonlinear structural change. Multi-linear regression models provide a suitable option for most bridge types, such as Dervilis et al.'s [98] robust Least Trimmed Square estimator. More complex nonlinear regression models require sufficient environmental data measurements to insure the accuracy and may be prone to over-fitting if not suitably defined. 
Research in the use of pattern recognition algorithms for the mitigation of environmental and operational effects has produced positive results, without the need to measure such variables. The utilisation of dimensionality reducing methodologies such as PCA and FA produce reliable results in linear investigations (Yan et al. [103] and Deraemaeker et al. [109], respectively) and provide a versatile platform for nonlinear applications (Lämsä \& Raiko's [110] non-linear FA application on the Z24 bridge, Nguyen et al. [113]'s KPCA application on the Champangshiehl Bridge). However, the careful selection of data distribution parameters and number of extracted principle components/common factors is required for successful applications.

In terms of the operational-induced effects on modal-based DSFs, this paper highlighted the caution of using frequency domain transformations that assume linear stationary structural response, as the vehicle-induced vibration of damaged bridges can be highly non-linear and non-stationary. For this reason, the authors highlighted the work by Moughty \& Casas [130], who investigate the use of HHT for the early stage damage detection in bridges subjected to operational loading.

The improvement and efficient utilization of machine learning algorithms for damage detection has been shown to improve the performance of modal-based DSFs. For instance, Chang \& Kim's [77] use of the Mahalanobis-Taguchi System, which combines multiple modal-based DSFs at once to enhance their collective damage sensitivity and performance consistency when applied to a steel truss bridge subjected to vehicle induced excitation. Dervilis et al. $[98,136]$ demonstrated the need for robust methods of outlier detection for supervised learning techniques to ensure that training datasets are not contaminated with outliers, by incorporating the Minimum Covariance Determinate and the Minimum Volume Enclosing Ellipsoid into standard outlier detection methods on the Z-24 Bridge.

Finally, for the advancement of SHM in bridges, this paper emphasized the necessity to explore and investigate alternative options to modal-based DSFs. In this regard, Moughty \& Casas [138] assessed numerous vibration-based DSFs on the S101 Bridge in Austria and discovered that DSFs that incorporated a vibration energy variable with an empirical frequency denominator exhibited significant damage sensitivity and resolution. Vibration-based DSFs were also shown to be suitable for use in real-time condition assessments by Santos et al. [149] through the use of robust online clustering on the Samora Machel Bridge. For time-series-based DSFs, Cross et al. $[169,170]$ exhibited the Cointegration technique, which shows great potential for bridge SHM problems, as it is suitable for non-stationary applications and has been recently advanced to nonlinear problems on the Z-24 Bridge.

Overall, the advancement of data processing techniques and an increased understanding of the wider bridge SHM problem with all its challenges, modal-based or otherwise, is advancing the field towards numerous damage identification solutions. To continue this course of progression toward network-wide applications, it is preferable that researchers consider robust methods of investigation and utilise real bridge data subjected to environmental and operational conditions where possible.

Acknowledgments: This project has received funding from the European Union's Horizon 2020 research and innovation programme under the Marie Skłodowska-Curie grant agreement No. 642453.

Conflicts of Interest: The authors declare no conflict of interest.

\section{References}

1. Rodrigues, F.; Casas, J.R.; Almeida, P. Fatigue-Safety assessment of RC bridges: Application to the Brazilian highway network. Struct. Infrastruct. Eng. 2013, 9, 601-616. [CrossRef]

2. Everett, T.; Weykamp, P.; Capers, H.; Cox, W.; Drda, T.; Hummel, L.; Jensen, P.; Juntunen, D.; Kimball, T.; Washer, G. Bridge Evaluation Quality Assurance in Europe; Technical report Document, FHWA-PL-08-016; U.S.D.O.T.: Washington, DC, USA.

3. Casas, J.R. European Standardization of Quality Specification for Roadway Bridges: An Overview. In Proceedings of the 8th International Conference on Bridge Maintenance, Safety and Management, Foz do Iguaçu, Brazil, 26-30 June 2016. 
4. Matos, J.; Casas, J.R.; Fernades, S. COST Action TU1406 quality specifications for roadway bridges (BridgeSpec). In Proceedings of the 8th International Conference on Bridge Maintenance, Safety and Management, Foz do Iguaçu, Brazil, 26-30 June 2016.

5. Elfgren, L. Benchmark of new technologies to extend the life of elderly rail infrastructure: Deliverable D1.1 of the MAINLINE Project. 2013.

6. Krieger, J.; Holst, R. Aging highway bridges-Challenges for owners and operators. In Proceedings of the 8th International Conference on Bridge Maintenance, Safety and Management, Foz do Iguaçu, Brazil, 26-30 June 2016.

7. Casas, J.R. Assessment and monitoring of existing bridges to avoid unnecessary strengthening or replacement. In Proceedings of the International IABMAS Conference on Bridge Maintenance, Safety and Management, 11-15 July 2010; CRC Press: Philadelphia, PA, USA, 2010; pp. 2261-2269.

8. Frangopol, D.M.; Saydam, D.; Kim, S. Maintenance, management, life-cycle design and performance of structures and infrastructures: A brief review. Struct. Infrastruct. Eng. 2015, 8, 1-25. [CrossRef]

9. Wang, C.H.; Chen, W.Z.; Chen, A.R. Damage safety assessment and maintenance management strategy of bridges. J. Traffic Transp. Eng. 2002, 2, 21-28.

10. Catbas, F.N.; Susoy, M.; Frangopol, D.M. Structural health monitoring and reliability estimation: Long span truss bridge application with environmental monitoring data. Eng. Struct. 2008, 30, 2347-2359. [CrossRef]

11. Xia, H.W.; Ni, Y.Q.; Wong, K.Y.; Ko, J.M. Reliability-based condition assessment of in-service bridges using mixture distribution models. Comput. Struct. 2012, 106-170, 204-213. [CrossRef]

12. Chen, X.; Omenzetter, P. A Framework for Reliability Assessment of an in-Service Bridge Using Structural Health Monitoring Data. Key Eng. Mater. 2013, 558, 39-51. [CrossRef]

13. Frangopol, D.M.; Strauss, A.; Kim, S. Bridge reliability assessment based on monitoring. J. Bridge Eng. 2008, 13, 258-270. [CrossRef]

14. Mori, Y.; Ellingwood, B. Methodology for Reliability Based Condition Assessment: Application to Concrete Structures in Nuclear Plants; Oak Ridge National Lab.: Oak Ridge, TN, USA, 1993.

15. Enright, M.P.; Frangopol, D.M. Probabilistic analysis of resistance degradation of reinforced concrete bridge beams under corrosion. Eng. Struct. 1998, 20, 960-971. [CrossRef]

16. Yang, D.Y.; Frangopol, D.M.; Teng, J.G. Reliability-Based Scheduling and Selection of Maintenance Actions with Application to the FRP Strengthening of RC Bridge Girders. In Proceedings of the 8th International Conference on Bridge Maintenance, Safety and Management, Foz do Iguaçu, Brazil, 26-30 June 2016.

17. Barone, G.; Frangopol, D.M. Reliability, risk and lifetime distributions as performance indicators for lifecycle maintenance of deteriorating structures. Reliab. Eng. Syst. Saf. 2014, 123, 21-37. [CrossRef]

18. Doebling, S.; Farrar, C.R.; Prime, M.B.; Shevitz, D. Damage Identification and Health Monitoring of Structural and Mechanical Systems from Changes in Their Vibration Characteristics: A Literature Review; Los Alamos National Laboratory Report LA-13070-MS; Los Alamos National Laboratory: Los Alamos, NM, USA, 1996.

19. Doebling, S.; Farrar, C.R.; Prime, M.B. A summary of vibration-based damage identification methods. Shock Vib. Dig. 1998, 30, 91-105. [CrossRef]

20. Chang, P.C.; Flatau, A.; Liu, S.C. Health Monitoring of Civil Infrastructure. Struct. Health Monit. 2003, 2, 257-267. [CrossRef]

21. Sohn, H.; Farrar, C.R.; Hemez, F.; Czarnecki, J. A Review of Structural Health Monitoring Literature from 1996-2001; Los Alamos National Laboratory Report LA-13976-MS; Los Alamos National Laboratory: Los Alamos, NM, USA, 2003.

22. Carden, E.P.; Fanning, P. Vibration Based Condition Monitoring: A Review. Struct. Health Monit. 2004, 3, 355-377. [CrossRef]

23. Barke, D.; Chiu, W.K. Structural Health Monitoring in the Railway Industry: A Review. Struct. Health Monit. 2005, 4, 81-93. [CrossRef]

24. Ou, J.; Li, H. Structural Health Monitoring in mainland China: Review and Future. Struct. Health Monit. 2010, 9, 219-231. [CrossRef]

25. Farrar, C.R.; Worden, K. An Introduction to Structural Health Monitoring. Philos. Trans. R. Soc. A Math. Phys. Eng. Sci. 2007, 365, 303-315. [CrossRef] [PubMed]

26. Roshan, P.; Kumar, A.; Tewatia, D.; Pal, S. Review Paper on Structural Health Monitoring: Its Benefit and Scope in India. J. Civ. Eng. Environ. Technol. 2015, 2, 109-112. 
27. Li, H.N.; Yi, T.H.; Ren, L.; Li, D.S.; Huo, L.S. Reviews on innovations and applications in structural health monitoring for infrastructures. Struct. Monit. Maint. 2014, 1, 1-45. [CrossRef]

28. Yan, Y.J.; Cheng, L.; Wu, Z.Y.; Yam, L.H. Development in vibration-based structural damage detection techniques. Mech. Syst. Signal Process. 2007, 21, 2198-2211. [CrossRef]

29. Rytter, A. Vibration Based Inspection of Civil Engineering Structures. Ph.D. Thesis, University of Aalborg, Aalborg, Denmark, 1993.

30. Limongelli, M.P.; Chatzi, E.; Dohler, M.; Lombaert, G.; Reynders, E. Towards extraction of vibration-based damage indicators. In Proceedings of the 8th European Workshop on Structural Health Monitoring (EWSHM 2016), Spain, Bilbao, 5-8 July 2016.

31. Adams, R.D.; Cawley, P.; Pye, C.J.; Stone, B.J. A vibration technique for non-destructively assessing the integrity of structures. J. Mech. Eng. Sci. 1978, 20, 93-100. [CrossRef]

32. Cawley, P.; Adams, R.D. The location of defects in structures from measurements of natural frequencies. J. Strain Anal. 1979, 14, 49-57. [CrossRef]

33. Salawu, O.S. Detection of structural damage through changes in frequency: A review. Eng. Struct. 1997, 19, 718-723. [CrossRef]

34. Lee, Y.S.; Chung, M.J. A study on crack detection using eigenfrequency test data. Comput. Struct. 2000, 77, 327-342. [CrossRef]

35. Kim, J.T.; Ryu, Y.S.; Cho, H.M.; Stubbs, N. Damage identification in beam-type structures: Frequency-based method vs. mode-shape based method. Eng. Struct. 2003, 25, 57-67. [CrossRef]

36. Casas, J.R.; Aparicio, A.C. Structural damage identification from dynamic-test data. J. Struct. Eng. 1995, 120, 2437-2450. [CrossRef]

37. Vestroni, F.; Capecchi, D. Damage evaluation in cracked vibrating beams using experimental frequencies and finite element models. J. Vib. Control 1996, 2, 69-86. [CrossRef]

38. Pau, A.; Greco, A.; Vestroni, F. Numerical and experimental detection of concentrated damage in a parabolic arch by measured frequency variations. J. Vib. Control 2011, 17, 605-614. [CrossRef]

39. Jeary, A.P.; Ellis, B.R. Non-destructive in-situ testing using dynamic techniques. In Proceedings of the 3rd International Conference on Tall Buildings, Hong Kong, China, 10-15 December 1984; pp. 76-81.

40. Yamaguchi, H.; Matsumoto, Y.; Kawarai, K.; Dammika, A.J.; Shahzad, S.; Takanami, R. Damage detection based on modal damping change in bridges. In Proceedings of the ICSBE'12, Kandy, Sri Lanka, 14-16 December 2013.

41. William, C.; Salawu, O.S. Damping as a damage indication parameter. In Proceedings of the 15th International Modal Analysis Conference, Tokyo, Japan, 1-4 September 1997; pp. 1531-1536.

42. Farrar, C.R.; Baker, W.E.; Dove, R.C. Dynamic parameter similitude for concrete models. ACI Struct. J. 1994, 91, 90-99.

43. Eyre, R.; Tily, G.P. Damping measurements on steel and composite bridges. In Proceedings of the DOE and DOT TRRL Symposium on Dynamic Behaviour of Bridges, Crowthorne, UK, 19 May 1977.

44. Farrar, C.R.; James, G.H. System identification from ambient vibration measurements on a bridge. J. Sound Vib. 1997, 205, 1-18. [CrossRef]

45. Allemang, R.J.; Brown, D.L. A correlation coefficient for modal vector analysis. In Proceedings of the 1st SEM International Modal Analysis Conference, Orlando, FL, USA, 8-10 November 1982.

46. Kim, J.H.; Jeon, H.S.; Lee, C.W. Application of the modal assurance criteria for detecting and locating structural faults. In Proceedings of the 10th International Modal Analysis Conference, San Diego, CA, USA, 3-7 February 1992; pp. 536-540.

47. Salawu, O.S.; Williams, C. Bridge assessment using forced-vibration testing. J. Struct. Eng. 1995, 121, $161-173$. [CrossRef]

48. Salgado, R.; Cruz, P.J.S.; Ramos, L.F.; Lourenco, P.B. Comparison between damage detection methods applied to beam structures. In Proceedings of the IABMAS'06, Porto, PT, USA, 16-19 July 2006.

49. Balsamo, L.; Mukhopadhyay, S.; Betti, R.; Lus, H. Damage Detection Using Flexibility Proportional Coordinate Modal Assurance Criterion. In Topics in Modal Analysis; Springer: New York, NY, USA, 2013; Volume 7. [CrossRef]

50. Zhao, J.; Zhang, L. Structural damage identification based on the modal data change. Int. J. Eng. Manuf. 2012, 4, 59-66. [CrossRef] 
51. Pandey, A.K.; Biswas, M.; Samman, M.M. Damage detection from changes in curvature mode shapes. J. Sound Vib. 1991, 145, 321-332. [CrossRef]

52. Abdel Wahab, M.M.; De Roeck, G. Damage detection in bridges using modal curvatures: Application to a real damage scenario. J. Sound Vib. 1999, 226, 217-235. [CrossRef]

53. Ho, Y.K.; Ewins, D.J. On structural damage identification with mode shapes. In Proceedings of the European COST F3 Conference on System Identification \& Structural Health Monitoring, Madrid, Spain, 6-9 June 2000; pp. 677-684.

54. Farrar, C.R.; Worden, K. Structural Health Monitoring - A Machine Learning Perspective, 1st ed.; John Wiley \& Sons, Ltd.: Chichester, West Sussex, UK, 2013; ISBN: 978-1-119-99433-6.

55. Hamming, R. Digital Filters, 3rd ed.; Prentice Hall: Englewood Cliffs, NJ, USA, 1989; ISBN: 10: 0132128128.

56. Sazonov, E.; Klinkhachorn, P. Optimal spatial sampling interval for damage detection by curvature or stain energy mode shapes. J. Sound Vib. 2005, 285, 783-801. [CrossRef]

57. Chance, J.; Tomlinson, G.R.; Worden, K. A simplified approach to the numerical and experimental modelling of the dynamics of a cracked beam. In Proceedings of the 12th International Modal Conference, 31 January-3 February 1994; pp. 778-785.

58. Capecchi, D.; Ciambella, J.; Pau, A.; Vestroni, F. Damage identification in a parabolic arch by means of modal frequencies, shapes and curvatures. Meccanica 2016, 51, 2847-2859. [CrossRef]

59. Stubbs, N.; Kim, J.T.; Topole, K. An efficient and robust algorithm for damage localization in offshore platforms. In Proceedings of the ASCE 10th Structures Congress, 13-15 April 1992; pp. 543-546.

60. Yam, L.H.; Leung, T.P.; Li, D.B.; Xue, K.Z. Theoretical and experimental study of modal analysis. J. Sound Vib. 1996, 191, 251-260. [CrossRef]

61. Cornwell, P.; Doebling, S.; Farrar, C. A strain-energy-based damage detection method for plate-like structures. J. Sound Vib. 1999, 224, 359-374. [CrossRef]

62. Duffey, T.; Doebling, S.; Farrar, C.; Baker, W.E.; Rhee, W.H. Vibration-based damage identification in structures exhibiting axial and torsional response. J. Vib. Acoust. 2001, 123, 84-91. [CrossRef]

63. Pandey, A.K.; Biswas, M. Damage detection in structures using changes in flexibility. J. Sound Vib. 1994, 169, 223-236. [CrossRef]

64. Toksoy, T.; Aktan, A. Bridge-condition assessment by modal flexibility. Exp. Mech. 1994, 34, 271-278. [CrossRef]

65. Wang, J.Y.; Ko, J.M.; Ni, Y.Q. Modal sensitivity analysis of Tsing Ma Bridge for structural damage detection. In Proceedings of the SPIE's 5th Annual International Symposium on Nondestructive Evaluation and Health Monitoring of Aging Infrastructure, International Society for Optics and Photonics, 5-9 March 2000; pp. 300-311.

66. Shih, H.W.; Thambiratnam, D.; Chan, T.H.T. Vibration based structural damage detection in flexural members using multi-criteria approach. J. Sound Vib. 2009, 323, 645-661. [CrossRef]

67. Doebling, S.W.; Farrar, C.R. Computation of structural flexibility for bridge health monitoring using ambient modal data. In Proceedings of the 11th ASCE Engineering Mechanics Conference, Fort Lauderdale, FL, USA, 20-22 May 1996; pp. 1114-1117.

68. Gao, Y.; Spencer, B. Damage localization under ambient vibration using changes in flexibility. Earthq. Eng. Eng. Vib. 2002, 1, 136-144. [CrossRef]

69. Zhang, Z.; Aktan, A.E. The damage indices for constructed facilities. In Proceedings of the International Modal Analysis Conference, Nashville, TN, USA, 13-16 February 1995; Volume 13, pp. 1520-1529.

70. Lu, Q.; Ren, G.; Zhao, Y. Multiple damage location with flexibility curvature and relative frequency change for beam structures. J. Sound Vib. 2002, 253, 1101-1114. [CrossRef]

71. Talebinejad, I.; Fischer, C.; Ansari, F. Numerical Evaluation of vibration-based methods for damage assessment of cable-stayed bridges. Comput.-Aided Civ. Infrastruct. Eng. 2011, 26, 239-251. [CrossRef]

72. Ndambi, J.M.; Vantomme, J.; Harri, K. Damage assessment in reinforced concrete beams using eigenfrequencies and mode shape derivatives. Eng. Struct. 2002, 24, 501-515. [CrossRef]

73. Cruz, P.J.S.; Salgado, R. Performance of Vibration-Based Damage Detection Methods in Bridges. Comput.-Aided Civ. Infrastruct. Eng. 2008, 24, 62-79. [CrossRef]

74. Fan, W.; Qiao, P. Vibration-based Damage Identification Methods: A Review and Comparative Study. Struct. Health Monit. 2011, 10, 83-111. [CrossRef] 
75. Peeters, B.; Roeck, G.D. One-year monitoring of the Z24-Bridge: Environmental effects versus damage events. Earthq. Eng. Struct. Dyn. 2001, 30, 149-171. [CrossRef]

76. Askegaard, V.; Mossing, P. Long term observation of RC-bridge using changes in natural frequency. Nord. Concr. Res. 1988, 7, 20-27.

77. Cornwell, P.; Farrar, C.R.; Doebling, S.W.; Shoh, H. Environmental variability of modal properties. Exp. Tech. 1999, 23, 45-48. [CrossRef]

78. Xu, Y.L.; Chen, B.; Ng, C.L.; Wong, K.Y.; Chan, W.Y. Monitoring temperature effect on a long suspension bridge. Struct. Control Health Monit. 2010, 17, 632-653. [CrossRef]

79. Kim, J.T.; Park, J.H.; Lee, B.J. Vibration-based damage monitoring in model plate-girder bridges under uncertain temperature conditions. Eng. Struct. 2007, 29, 1354-1365. [CrossRef]

80. Giraldo, D.F.; Dyke, S.J.; Caicedo, J.M. Damage detection accommodating varying environmental conditions. Struct. Health Monit. 2006, 5, 155-172. [CrossRef]

81. Xia, Y.; Hao, H.; Zanardo, G.; Deeks, A.J. Long term vibration monitoring of a RC slab: Temperature and humidity effects. Eng. Struct. 2006, 28, 441-452. [CrossRef]

82. Farrar, C.R.; Baker, W.E.; Bell, T.M.; Cone, K.M.; Darling, T.W.; Duffey, T.A.; Eklund, A.; Migliori, A. Dynamic Characterization and Damage Detection in the I-40 Bridge over the Rio Grande; Los Alamos National Laboratory Report: LA-12767-MS; LANL: Los Alamos, NM, USA, 1994. [CrossRef]

83. Cross, E.J.; Koo, K.Y.; Brownjohn, J.M.W.; Worden, K. Long-term Monitoring and Data Analysis of the Tamar Bridge. Mech. Syst. Signal Process. 2013, 35, 16-34. [CrossRef]

84. Soyoz, S.; Feng, M.Q. Long-term Monitoring and Identification of Bridge Structural Parameters. Comput.-Aided Civ. Infrastruct. Eng. 2009, 24, 82-92. [CrossRef]

85. Kim, C.W.; Kawatani, M.; Hao, J. Modal parameter identification of short span bridges under a moving vehicle by means of multivariate AR model. Struct. Infrastruct. Eng. 2012, 8, 459-472. [CrossRef]

86. Kim, C.Y.; Jung, D.S.; Kim, N.S.; Yoon, J.G. Effect of vehicle mass on the measured dynamic characteristics of bridges from traffic-induced test. In Proceedings of the IMAC XIX-19th International Modal Analysis, Los Angeles, CA, USA, 5-8 February 2001; pp. 1106-1110.

87. De Roeck, G.; Maeck, J.; Michielsen, T.; Seynaeve, E. Traffic-induced shifts in modal properties of bridges. Proc. Soc. Photo-Opt. Instrum. Eng. 2002, 4753, 630-636.

88. Zhang, Q.W.; Fan, L.C.; Yuan, W.C. Traffic-induced variability in dynamic properties of cable-stayed bridge. Earthq. Eng. Struct. Dyn. 2002, 31, 2015-2021. [CrossRef]

89. Zhou, G.D.; Yi, T.H. A summary review of correlations between temperatures and vibration properties of long-span bridges. Math. Probl. Eng. 2014, 2014. [CrossRef]

90. Sohn, H. Effects of environmental and operational variability on structural health monitoring. Philos. Trans. R. Soc. 2007, 365, 539-560. [CrossRef] [PubMed]

91. Alcover, I.F.; Chryssanthopoulos, M.K.; Andersen, J.E. Regression models for structural health monitoring of welded bridge joints based on temperature, traffic and strain measurements. Struct. Health Monit. 2015, 14, 648-662. [CrossRef]

92. Song, Y.S.; Ding, Y.L. Fatigue monitoring and analysis of orthotropic steel deck considering traffic volume and ambient temperature. Sci. China Technol. Sci. 2013, 56, 1758-1766. [CrossRef]

93. Znidaric, A.; Lavric, I.; Kalin, J. Measurements of bridge dynamics with a bridge weigh-in-motion system. In Proceedings of the 5th international Conference on Weigh-in-Motion, Paris, France, 19-22 May 2008; pp. 388-397.

94. Brady, S.P.; O’Brien, E.J.; Znidaric, A. Effective of vehicle velocity on the dynamic amplification of a vehicle crossing a simply supported bridge. J. Bridge Eng. 2006, 11, 241-249. [CrossRef]

95. O'Brien, E.J.; Rattigan, P.; Gonzales, A.; Dowling, J.; Znidaric, A. Characteristic dynamic traffic load effects in bridges. Eng. Strucut. 2009, 31, 1607-1612. [CrossRef]

96. Xia, Y.; Chen, B.; Weng, S.; Ni, Y.Q.; Xu, Y.L. Temperature effect on vibration properties of civil structures: A literature review and case studies. J. Civ. Struct. Health Monit. 2012, 2, 29-46. [CrossRef]

97. Liu, C.; DeWolf, J.T.; Kim, J.H. Development of a baseline for structural health monitoring for a curved post-tensioned concrete box-girder bridge. Eng. Struct. 2009, 31, 3107-3115. [CrossRef]

98. Dervilis, N.; Worden, K.; Cross, E.J. On robust regression analysis as a means of exploring environmental and operational conditions for SHM data. J. Sound Vib. 2015, 347, 279-296. [CrossRef] 
99. Rousseeuw, P.J.; Van Driessen, K. A fast algorithm for the Minimum Covariance Determinant estimator. Technometrics 1999, 41, 212-223. [CrossRef]

100. Vanlanduit, E.; Parloo, B.; Cauberghe, P.; Verboven, P. A robust singular value decomposition for damage detection under changing operating conditions and structural uncertainties. J. Sound Vib. 2005, 284, 1033-1050. [CrossRef]

101. Ding, Y.L.; Li, A.Q. Temperature-induced variations of measured modal frequencies of steel box girder for a long-span suspension bridge. Int. J. Steel Struct. 2011, 11, 145-155. [CrossRef]

102. Macdonald, J.H.G. Identification of the Dynamic Behaviour of a Cable-Stayed Bridge from Full-Scale Testing during and after Construction. Ph.D. Thesis, University of Bristol, Bristol, UK, 2000.

103. Yan, A.M.; Kerschen, G.; De Boe, P.; Golinval, J.C. Structural damage diagnosis under varying environmental conditions-Part I: A linear analysis. Mech. Syst. Signal Process. 2005, 19, 847-864. [CrossRef]

104. Yan, A.M.; Kerschen, G.; De Boe, P.; Golinval, J.C. Structural damage diagnosis under changing environmental conditions-Part II: Local PCA for nonlinear cases. Mech. Syst. Signal Process. 2005, 19, 865-880. [CrossRef]

105. Kullaa, J. Statistical analysis of the damage detection performance under environmental or operational influences. In Proceedings of the 9th International Conference on Structural Dynamics, EURODYN, Porto, Portugal, 30 June-2 July 2014.

106. Brown, J.D. Principal Components Analysis and Exploratory Factor Analysis-Definitions, Differences and Choices; Shiken: JALT Testing \& Evaluation SIG Newsletter: Shizuoka, Japan, 2009.

107. Kullaa, J. Structural health monitoring under variable environmental or operational conditions. In Proceedings of the Second European Workshop on Structural Health Monitoring, Munich, Germany, 7-9 July 2004; pp. 1262-1269.

108. Kullaa, J. Vibration-Based Structural Health Monitoring under Variable Environmental or Operational Conditions; Chapter in New Trends in Vibration Based Structural Health Monitoring; Springer: Wien, Austria, 2010; pp. 107-181. [CrossRef]

109. Deraemaeker, A.; Reynders, E.; de Roeck, G.; Kullaa, J. Vibration-based structural health monitoring using output-only measurements under changing environment. Mech. Syst. Signal Process. 2008, 22, 34-56. [CrossRef]

110. Lämsä, V.; Raiko, T. Novelty detection by nonlinear factor analysis for structural health monitoring. In Proceedings of the International Workshop on Machine Learning for Signal Processing (MLSP), 2010 IEEE International Workshop on, Kittilä, Finland, 29 August-1 September 2010; IEEE: Kittilä, Finland; pp. 468-473.

111. Hsu, T.-Y.; Loh, C.-H. Damage detection accommodating nonlinear environmental effects by nonlinear principal component analysis. Struct. Control Health Monit. 2010, 17, 338-354. [CrossRef]

112. Kramer, M.A. Nonlinear principal component analysis using autoassociative neural networks. AIChE J. 1991, 37, 233-243. [CrossRef]

113. Nguyen, V.H.; Mahowald, J.; Golinval, J.C.; Maas, S. Damage Detection in Civil Engineering Structure Considering Temperature Effect. Dyn. Civ. Struct. 2014, 4, 187-196. [CrossRef]

114. Oh, C.K.; Sohn, H.; Bae, I.-H. Statistical novelty detection within the Yeongjong suspension bridge under environmental and operational variations. Smart Mater. Struct. 2009. [CrossRef]

115. Santos, A.D.; Silva, M.F.M.; Sales, C.S.; Costa, J.C.W.A.; Figueriredo, E. Applicability of linear and nonlinear principal component analysis for damage detection. In Proceedings of the Instrumentation and Measurement Technology Conference (I2MTC), Pisa, Italy, 11-14 May 2015.

116. Santos, A.; Figueiredo, E.; Silva, M.F.M.; Sales, C.S.; Costa, J.C.W.A. Machine learning algorithms for damage detection: Kernel-based approaches. J. Sound Vib. 2016, 363, 584-599. [CrossRef]

117. Reynders, E.; Wursten, G.; De Roeck, G. Output-only structural health monitoring in changing environmental conditions by means of nonlinear system identification. Struct. Health Monit. 2014, 13, 82-93. [CrossRef]

118. Shannon, C.E. A mathematical theory of communication. Bell Syst. Tech. J. 1948, 27, 379-423. [CrossRef]

119. Li, H.; Li, S.L.; Ou, J.P.; Li, H.W. Modal identification of bridges under varying environmental conditions: Temperature and wind effects. Struct. Control Health Monit. 2010, 17, 499-512. [CrossRef]

120. Jin, C.; Li, J.; Jang, S.; Sun, X.; Christenson, R. Structural damage detection for in-service highway bridge under operational and environmental variability. Sens. Smart Struct. Technol. Civ. Mech. Aerosp. Syst. 2015, 94353A. [CrossRef] 
121. Jin, C.; Jang, S.; Sun, X.; Li, J.; Christenson, R. Damage detection of a highway bridge under severe temperature changes using extended Kalman filter trained neural network. J. Civ. Struct. Health Monit. 2016, 6, 545-560. [CrossRef]

122. Kaloop, M.R.; Hu, J.W.; Elbeltagi, E. Time-Series and Frequency-Spectrum Correlation Analysis of Bridge Performance Based on a Real-Time Strain Monitoring System. ISPRS Int. J. Geo-Inf. 2016, 5, 61. [CrossRef]

123. Miao, S.; Koenders, E.; Knobbe, A. Automatic baseline correction of strain gauge signals. Struct. Control Health Monit. 2015, 22, 36-49. [CrossRef]

124. Follen, C.; Sanayei, M.; Brenner, B.; Vogel, R. Statistical bridge signatures. J. Bridge Eng. 2014. [CrossRef]

125. Huang, N.E.; Long, S.R.; Shen, Z. The mechanism for frequency downshift in nonlinear wave evolution. Adv. Appl. Mech. 1996, 32, 59-111. [CrossRef]

126. Chen, B.; Zhao, S.L.; Li, P.Y. Application of Hilbert-Huang transform in structural health monitoring: A state-of-the-art review. Math. Probl. Eng. 2014. [CrossRef]

127. Aied, H.; González, A.; Cantero, D. Identification of sudden stiffness changes in the acceleration response of a bridge to moving loads using ensemble empirical mode de-composition. Mech. Syst. Signal Process. 2016, 66-67, 314-338. [CrossRef]

128. Han, J.; Zheng, P.; Wang, H. Structural modal param-eter identification and damage diagnosis based on Hilbert-Huang transform. Earthq. Eng. Eng. Vib. 2014, 13, 101-111. [CrossRef]

129. Kunwar, A.; Jha, R.; Whelan, M.; Janoyan, K. Damage detection in an experimental bridge model using Hilbert-Huang transform of transient vibrations. Struct. Control Health Monit. 2013, 20, 1-15. [CrossRef]

130. Moughty, J.J.; Casas, J.R. Evaluation of the Hilbert Huang Transformation of Transient Signals for Bridge Condition Assessment. In Proceedings of the Annual European Safety and Reliability Conference (ESREL 2017), Portoroz, Slovenia, 18-22 June 2017. In press.

131. Mahalanobis, P.C. On the generalized distance in statistics. In Proceedings of the National Institute of Sciences, Calcutta, India, 16 April 1936; Volume 2, pp. 49-55.

132. Chang, K.C.; Kim, C.W. Modal-parameter identification and vibration-based damage detection of a damaged steel truss bridge. Eng. Struct. 2016, 122, 156-173. [CrossRef]

133. Taguchi, G.; Jugulum, R. New trends in multivariate diagnosis. Indian J. Stat. 2000, 62, 233-248.

134. Cudney, E.A.; Hong, J.; Jugulum, R.; Paryani, K.; Ragsdell, K.M.; Taguchi, G. An Evaluation of Mahalanobis-Taguchi System and Neural Network for Multivariate Pattern Recognition. J. Ind. Syst. Eng. 2007, 1, 139-150.

135. Moshtagh, N. Minimum volume enclosing ellipsoid. Convex Optim. 2005, 111, 112.

136. Dervilis, N.; Cross, E.J.; Barthorpe, R.J.; Worden, K. Robust methods of inclusive outlier analysis for structural health monitoring. J. Sound Vib. 2014, 333, 5181-5195. [CrossRef]

137. Figueiredo, E.; Park, G.; Farrar, C.R.; Worden, K.; Figueiras, J. Machine learning algorithms for damage detection under operational and environmental variability. Int. J. Struct. Health Monit. 2011, 10, 559-572. [CrossRef]

138. Moughty, J.J.; Casas, J.R. Performance Assessment of Vibration Parameters as Damage Indicators for Bridge Structures under Ambient Excitation. In Proceedings of the $X$ International Conference on Structural Dynamics (EURODYN 2017), Rome, Italy, 10-13 September 2017. In press.

139. Vienna Consulting Engineers (VCE). Progressive Damage Test S101 Flyover; Technical Report No. 08/2308; VCE: Vienna, Austria, 2009.

140. Nuttli, O.W. The Relation of Sustained Maximum Ground Acceleration and Velocity to Earthquake Intensity and Magnitude; Miscellaneous Paper S-73-1, Report 16; U.S. Army Corps of Engineers; Waterways Experiment Station: Vicksburg, MS, USA, 1979.

141. Rathje, E.M.; Faraj, F.; Russell, S.; Bray, J.D. Empirical Relationships for Frequency Content Parameters of Earthquake Ground Motions. Earthq. Spectra 2004, 20, 119-144. [CrossRef]

142. Kramer, S.L. Geotechnical Earthquake Engineering; Prentice-Hall: Upper Saddle River, NJ, USA, 1996; ISBN: 0133749436.

143. Arias, A. A Measure of Earthquake Intensity. In Seismic Design for Nuclear Power Plants, Hansen, R.J., Ed.; 1st ed.; MIT Press: Cambridge, MA, USA, 1970; pp. 438-483.

144. Araya, R.; Saragoni, R. Earthquake accelerogram destructiveness potential factor. In Proceedings of the 8th World Conference of Earthquake Engineering, San Francisco, CA, USA, 21-28 July 1984; Volume 2, pp. 835-841. 
145. Koch, H.W. Determining the effects of vibration in buildings. VDIZ 1953, 25, 744-747.

146. Meixedo, A.; Calçada, R.; Alves, V.; Ribeiro, D.; Cury, A. Damage Identification of a Railway Bridge Based on Genetic Algorithms. In Proceedings of the Eighth International Conference on Bridge Maintenance, Safety and Management (IABMAS 2016), Foz do Iguaçu, Brasil, 26-30 June 2016.

147. Kaloop, M.R.; Hu, J.W. Stayed-Cable Bridge Damage Detection and Localization Based on Accelerometer Health Monitoring Measurements. Shock Vib. 2015, 2015. [CrossRef]

148. Casas, J.R.; Rodrigues, F. Bridge condition and safety based on measured vibration level. In Proceedings of the International Association for Bridge and Structural Engineering, Helsinki, Finland, 11-12 February 2015.

149. Santos, J.P.; Orcesi, A.D.; Cremona, C.; Silverira, P. Baseline-free real-time assessment of structural changes. Struct. Infrastruct. Eng. Maint. Manag. Life-Cycle Des. Perform. 2013. [CrossRef]

150. Limongelli, M.P. Frequency response function interpolation for damage detection under changing environment. Mech. Syst. Signal Process. 2010, 24, 2898-2913. [CrossRef]

151. Limongelli, M.P. The Interpolation Damage Detection Method for frames under seismic excitation. J. Sound Vib. 2011, 330, 5474-5489. [CrossRef]

152. Ramesh Babu, T.; Sekhar, A.S. Detection of two cracks in a rotor-bearing system using amplitude deviation curve. J. Sound Vib. 2008, 314, 457-464. [CrossRef]

153. Zhang, Y.; Lie, S.T.; Xiang, Z. Damage detection method based on operating deflection shape curvature extracted from dynamic response of a passing vehicle. Mech. Syst. Signal Process. 2013, 35, 238-254. [CrossRef]

154. Sampaio, R.P.C.; Maia, N.M.M.; Silva, J.M.M. Damage detection using the frequency response function curvature method. J. Sound Vib. 1999, 226, 1029-1042. [CrossRef]

155. Ratcliffe, C.P. Damage detection using a modified Laplacian operator on mode shape data. J. Sound Vib. 1997, 4, 505-517. [CrossRef]

156. Ratcliffe, C.P. A frequency and curvature based experimental method for locating damage in structures. J. Vib. Acoust. 2000, 122, 324-329. [CrossRef]

157. Dilena, M.; Limongelli, M.P.; Morassi, A. Damage localization in bridges via the FRF interpolation method. Mech. Syst. Signal Process. 2015, 52-53, 162-180. [CrossRef]

158. Figueiredo, E.; Figueiras, J.; Park, G.; Farrar, C.R.; Worden, K. Influence of autoregressive model order on damage detection. Int. J. Comput.-Aided Civ. Infrastruct. Eng. 2011, 26, 225-238. [CrossRef]

159. Box, G.; Jenkins, G.; Reinsel, G. Time Series Analysis, Forecasting and Control, 3rd ed.; Prentice Hall: Englewood Cliffs, NJ, USA, 1994; ISBN: 978-1-118-67502-1.

160. Omenzetter, P.; Brownjohn, J.M.W. Application of time series analysis for bridge monitoring. Smart Mater. Struct. 2006, 15, 129-138. [CrossRef]

161. Kantz, H.; Schreiber, T. Nonlinear Time Series Analysis, 2nd ed.; Cambridge University Press: Cambridge, UK, 2003; ISBN: 0521529026.

162. Yao, R.; Pakzad, S.H. Autoregressive statistical pattern recognition algorithms for damage detection in civil structures. Mech. Syst. Signal Process. 2012, 31, 355-368. [CrossRef]

163. Gul, M.; Catbas, F.N. Statistical pattern recognition for structural health monitoring using time series modeling: Theory and experimental verifications. Mech. Syst. Sig. Process. 2009, 23, 2192-2204. [CrossRef]

164. Nair, K.K.; Kiremidjian, A.S. Time Series Based Structural Damage Detection Algorithm Using Gaussian Mixtures Modelling. ASME J. Dyn. Syst. Meas. Control 2007, 129, 258-293. [CrossRef]

165. Mei, Q.; Gül, M. Novel Sensor Clustering-Based Approach for Simultaneous Detection of Stiffness and Mass Changes Using Output-Only Data. J. Struct. Eng. 2015. [CrossRef]

166. Bernal, D.; Beck, J. Preface to the special issue on phase I of the IASC-ASCE structural health monitoring benchmark. J. Eng. Mech. 2004, 130. [CrossRef]

167. Chatzi, E.N.; Spiridonakos, M.D. Dealing with uncertainty in the monitoring of dynamically evolving systems. In Proceedings of the 7th International Conference on Structural Health Monitoring of Intelligent Infrastructure (SHMII), Torino, Italy, 1-3 July 2015.

168. Spiridonakos, M.D.; Chatzi, E.N. Metamodeling of structural systems with parametric uncertainty subject to stochastic dynamic excitation. Int. J. Earthq. Eng. Earthq. Eff. Struct. 2015, 8, 915-934. [CrossRef]

169. Cross, E.J.; Worden, K.; Sturgeon, R.; Chen, Q. A tutorial on cointegration for engineers-A tool for non-stationary time series analysis. In Proceedings of the 10th International Conference on Recent Advances in Structural Dynamics, Southampton, UK, 12-14 July 2010. 
170. Cross, E.J.; Worden, K.; Chen, Q. Cointegration: A novel approach for the removal of environmental trends in structural health monitoring data. Proc. Royal Soc. Lond. Math. Phys. Eng. Sci. 2011, 467, 2712-2732. [CrossRef]

171. Johansen, S. Likelihood-Based Inference in Cointegrated Vector Autoregressive Models; Oxford University Press: Oxford, UK, 1995; ISBN: 9780198774501.

172. Shi, H.; Worden, K.; Cross, E.J. A nonlinear cointegration approach with applications to structural health monitoring. J. Phys. Conf. Ser. 2016. [CrossRef]

(C) 2017 by the authors. Licensee MDPI, Basel, Switzerland. This article is an open access article distributed under the terms and conditions of the Creative Commons Attribution (CC BY) license (http:/ / creativecommons.org/licenses/by/4.0/). 